PREPARED FOR THE U.S. DEPARTMENT OF ENERGY, UNDER CONTRACT DE-AC02-76CH03073

PPPL-3763

PPPL-3763

UC-70

Models for Automated Tube Performance Calculations

by

C. Brunkhorst

December 2002

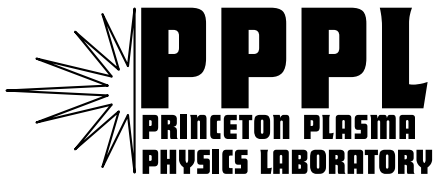

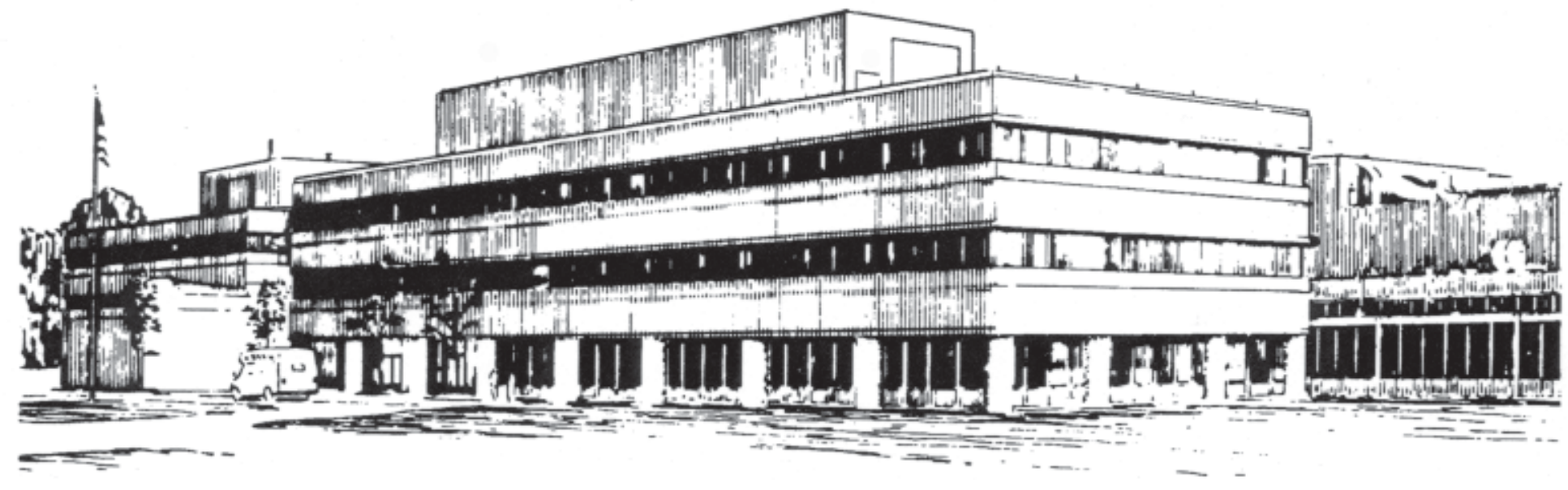

PRINCETON PLASMA PHYSICS LABORATORY PRINCETON UNIVERSITY, PRINCETON, NEW JERSEY 


\section{PPPL Reports Disclaimer}

This report was prepared as an account of work sponsored by an agency of the United States Government. Neither the United States Government nor any agency thereof, nor any of their employees, makes any warranty, express or implied, or assumes any legal liability or responsibility for the accuracy, completeness, or usefulness of any information, apparatus, product, or process disclosed, or represents that its use would not infringe privately owned rights. Reference herein to any specific commercial product, process, or service by trade name, trademark, manufacturer, or otherwise, does not necessarily constitute or imply its endorsement, recommendation, or favoring by the United States Government or any agency thereof. The views and opinions of authors expressed herein do not necessarily state or reflect those of the United States Government or any agency thereof.

\section{Availability}

This report is posted on the U.S. Department of Energy's Princeton Plasma Physics Laboratory Publications and Reports web site in Fiscal Year 2003. The home page for PPPL Reports and Publications is: http://www.pppl.gov/pub_report/

DOE and DOE Contractors can obtain copies of this report from:

U.S. Department of Energy

Office of Scientific and Technical Information

DOE Technical Information Services (DTIS)

P.O. Box 62

Oak Ridge, TN 37831

Telephone: (865) 576-8401

Fax: (865) 576-5728

Email: reports@adonis.osti.gov

This report is available to the general public from:

National Technical Information Service

U.S. Department of Commerce

5285 Port Royal Road

Springfield, VA 22161

Telephone: $1-800-553-6847$ or

(703) $605-6000$

Fax: (703) 321-8547

Internet: http://www.ntis.gov/ordering.htm 


\title{
Models for Automated Tube Performance Calculations
}

\author{
C. Brunkhorst, Princeton Plasma Physics Laboratory, P.O. Box 451, Princeton, New Jersey, 08543*
}

\begin{abstract}
High power RF systems, as typically used in fusion research devices, utilize vacuum tubes. Evaluation of vacuum tube performance involves data taken from tube operating curves. The acquisition of data from such graphical sources is a tedious process. A simple modeling method is presented that will provide values of tube currents for a given set of element voltages. These models may be used as subroutines in iterative solutions of amplifier operating conditions for a specific loading impedance.
\end{abstract}

\section{Introduction}

Chaffee analysis has long been used for the evaluation of amplifier operating conditions. This technique uses tube currents and voltages sampled at regular intervals during the RF cycle to provide a piecewise linear approximation of the currents over a 90 degree portion of the cycle. Tube current curves are used to obtain the data at the sampling points. The graphical nature of this data is a detriment to the full utilization of Chaffee analysis. As an example, it may be desired to obtain results for an amplifier operating at a specific plate load impedance. However, load impedance is found as a result of the analysis, so an iterative approach must be used. The need to obtain input data from tube curves for each iteration makes this impractical. The modeling method presented here removes this impediment.

\section{The Method}

Tube curves are published for either grounded grid or grounded cathode operation. An example will be shown using grounded grid curves for a typical tetrode (Fig. 1).

The $\mathrm{Y}$-axis is cathode to grid voltage $(V c g)$, and the $\mathrm{X}$-axis is plate to grid voltage $(V p g)$ in $\mathrm{kV}$. Each curve consists of the locus of points for a constant value of the current in question, plate grid and screen in the case of a tetrode. The curves are given for a range of discrete values of current.

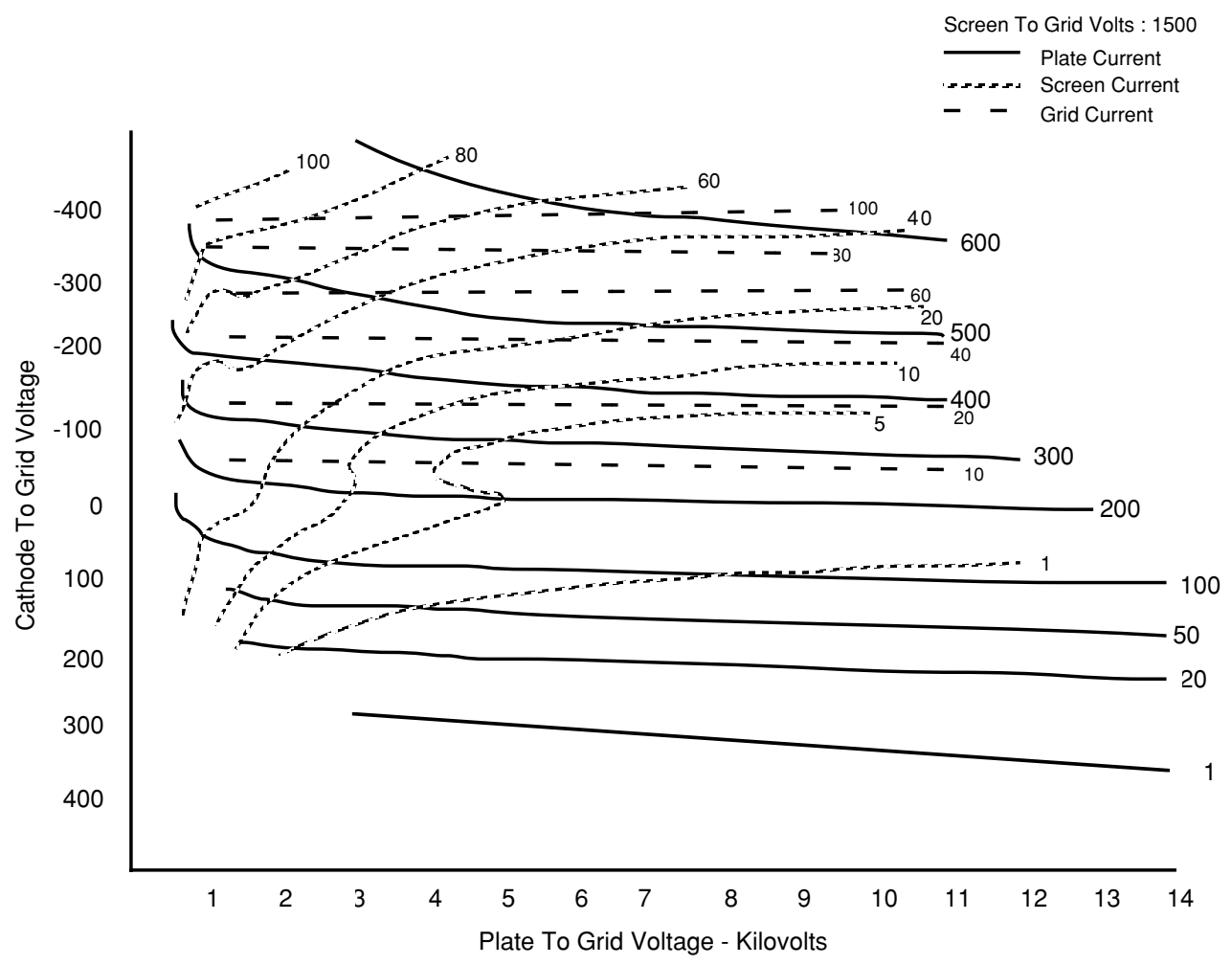

Figure 1

Constant current tube curves for a typical tetrode. 
The problem is: given values of $V c g$ and $V p g$, what will the current be for a particular tube element? At any arbitrary $V p g$, each constant current curve will be found at a particular $V c g$. In this example, data was taken for plate current, (Ip) at $V p g=10 \mathrm{kV}$, and the results are shown in table I.
Table I

$\begin{array}{cc}V c g & \mathrm{I} p \\ 340 & 1 \\ 230 & 20 \\ 170 & 50 \\ 110 & 100 \\ 10 & 200 \\ -60 & 300 \\ -140 & 400 \\ -220 & 500 \\ -360 & 600\end{array}$

This can be plotted as current vs. voltage, and a polynomial curve fit can be performed. A plot of the data from table I, and the resulting polynomial curve fit is shown in Fig. 2.

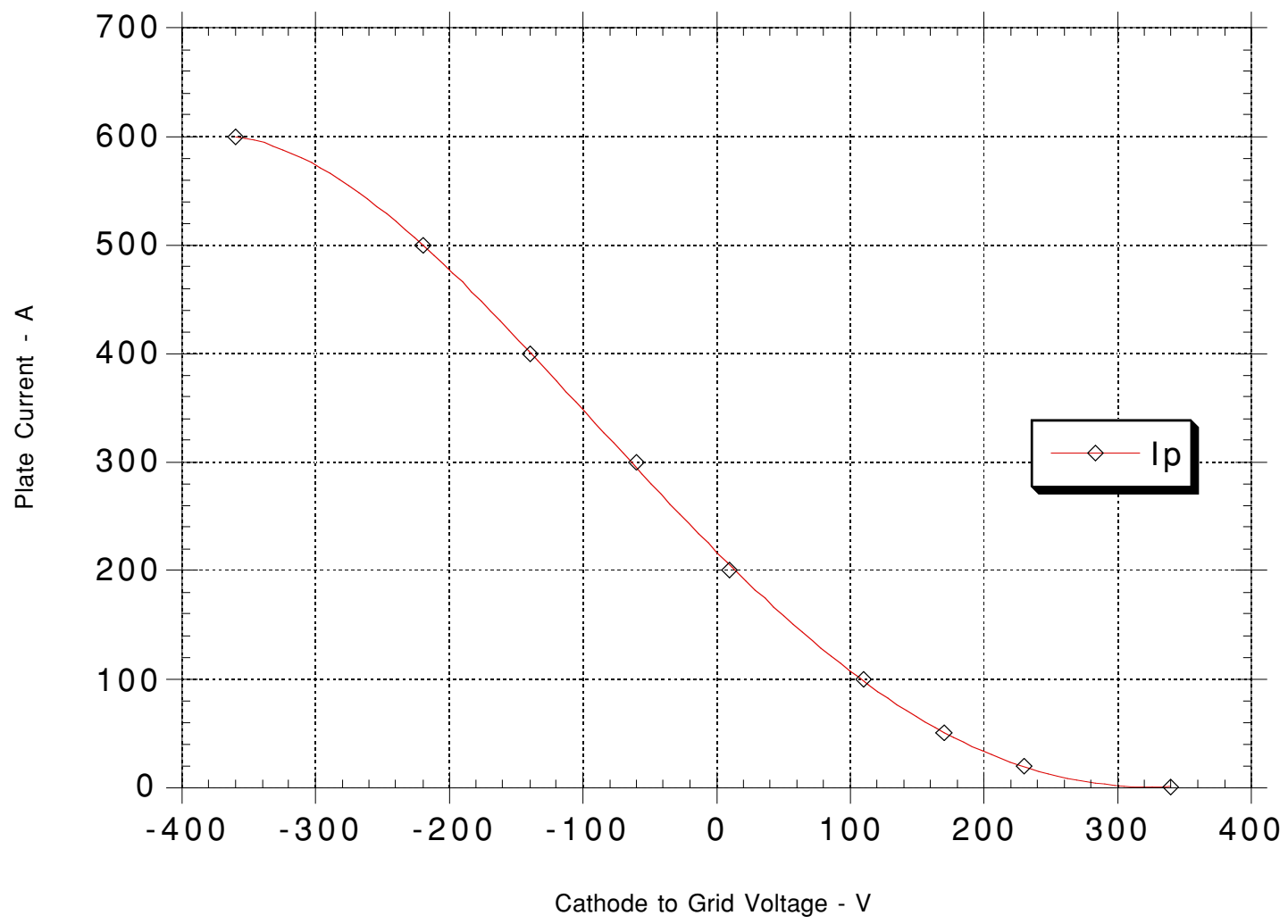

Figure 2

Plate current vs. cathode to grid voltage at $10 \mathrm{kV}$ plate voltage, with a plot of the polynomial curve fit for the data in table II. 
The order of the polynomial is chosen by trial and error, to provide the best fit to the data points. In the example, a fourth order polynomial results in a close match to the data. For this particular $V p g$, we now have an equation that will provide the value of the plate current for any $V c g$ :

$$
I p=M 0+M 1 * V c g+M 2 * V c g^{2}+M 3 * V c g^{3} \ldots
$$

At this point, some of the limitations of this approach must be mentioned. The goal is to reproduce the data contained in the original tube curve. It is therefore important to restrict the input data to the range of the values used in the curve fit. The polynomial can not be used to extrapolate behavior beyond this range. The curve fit will also give non-zero values of $I p$ for $V c g$ below cut off. A cut off limit is defined, and Ip set to zero if $V c g$ exceeds this limit. In this example, the $1 \mathrm{~A}$ plate current curve may be chosen as the cut off limit. Thus, for this example, $I p$ is set to 0 when:

$V c g>(7.14 * V p+269)$

Having created an equation for $I p$, this process can be repeated at regular intervals of $V p g, \Delta V p$. Equations now exist for $I p$ as a function of $V c g$ at multiples of $\Delta V p$. The tube model consists of the set of polynomial coefficients at intervals of Vpg as shown in table II.

\section{Table II}

$\begin{array}{llllll}\text { Vpg } & M 0 & M 1 & M 2 & M 3 & M 4 \\ 1 & 149.9 & -1.110 & .002932 & 1.453 \mathrm{e}-05 & 1.539 \mathrm{e}-08 \\ 2 & 171.4 & -1.124 & .0009835 & 4.051 \mathrm{e}-06 & 1.088 \mathrm{e}-09 \\ 3 & 186.4 & -1.192 & .0007355 & 4.851 \mathrm{e}-06 & 3.850 \mathrm{e}-09 \\ 4 & 192.7 & -1.157 & .0008050 & 3.146 \mathrm{e}-06 & 1.996 \mathrm{e}-10 \\ 5 & 195.2 & -1.174 & .0009574 & 3.055 \mathrm{e}-06 & -1.050 \mathrm{e}-09 \\ 6 & 199.5 & -1.184 & .0009725 & 3.041 \mathrm{e}-06 & -1.406 \mathrm{e}-09 \\ 7 & 201.0 & -1.209 & .001003 & 3.183 \mathrm{e}-06 & -1.605 \mathrm{e}-09 \\ 8 & 205.8 & -1.203 & .001003 & 3.058 \mathrm{e}-06 & -1.962 \mathrm{e}-09 \\ 9 & 213.5 & -1.206 & .0006653 & 3.110 \mathrm{e}-06 & 8.492 \mathrm{e}-10 \\ 10 & 214.9 & -1.208 & .0007318 & 3.006 \mathrm{e}-06 & 3.094 \mathrm{e}-10\end{array}$

To find $I p$ for a particular point, $(V p g, V c g)$, Ip is calculated with the equations for 2 adjacent values of $V p g$ from table II:

$$
\begin{aligned}
& V 1=\text { Integer Value }(V p g / \Delta V p) * \Delta V p \\
& V 2=V p 1+\Delta V p
\end{aligned}
$$

Tube curves don $t$ always extend to the maximum Vpg that may actually be used. It is reasonable to assume that the curves continue in a linear fashion. The curves may be extrapolated using the data at the highest values of $V p g$. So if $V p g \geq 10$, then:

$$
\begin{aligned}
& V 1=9 \\
& V 2=10
\end{aligned}
$$

Plate currents are now calculated using the equations from table II at $V p g=V 1$ and $V p g=V 2$ :

$$
I p 1=\mathrm{f}(V 1, V c g)
$$

$I p 2=\mathrm{f}(V 2, V c g)$

The final result is found by interpolation:

$I p=((V p g-V 1) / \Delta V p *(I p 2-I p 1))+I p 1$

Tube curves are created for a specific screen to grid voltage $(V s g)$. The model may be used for other values of $V s g$ in the following manner:

$K=V s g / V o$

Where $V o$ is the nominal screen to grid voltage for the tube curve used in the model. $K$ is used to transform $V p g$ and $V c g$ :

$V p g^{\prime}=V p g / K$

$V c g^{\prime}=V c g / K$

$V p g^{\prime}$ and $V c g^{\prime}$ are now used as input data for the model, and the current $I p^{\prime}$ is computed. The plate current is now calculated from $I p^{\prime}$ :

$I \mathrm{p}=I \mathrm{p}^{\prime} * K^{1.5}$

The same method may be used to obtain screen and grid currents. Plate and grid currents are obtained with good accuracy. Due to the usually convoluted nature of the constant current curves for the screen, the results are not as good as for plate and grid current.

\section{Applications}

It is a simple matter to employ tube models as subroutines in Chaffee analysis. The model is used to obtain plate, screen and grid current values every 15 degrees over one quarter of the RF cycle. From this data, DC and peak fundamental RF currents are calculated. From these currents power output, plate, grid and screen dissipation, and drive power may be calculated. A complete description of Chaffee analysis may be found in [1].

When Chaffee analysis is performed, the peak RF voltage applied to the cathode (or grid for the common cathode configuration), and the minimum instantaneous plate voltage are required input parameters. If these are chosen arbitrarily, desired output power and plate impedance can not be predicted accurately. An iterative approach can be used to predict tube behavior at specific loading and power levels. Given a desired output power $(\mathrm{Po})$, and plate impedance, the plate swing can be calculated. The RF voltage applied to the cathode can be increased at each iteration by an amount, $\Delta V c$, and the output power $(P x)$ calculated. This is repeated until:

$\operatorname{Sign}(\Delta V c) *(P o-P x)<0$

Then:

$\Delta V c=\Delta V c *-0.5$ 


\begin{tabular}{|c|c|c|c|c|c|c|c|}
\hline ANODE & & & & & & & \\
\hline SCREEN & 1000 & & & & & & \\
\hline BIAS & -500 & & & & & & \\
\hline IMPEDANCE & 110 & & & & & & \\
\hline \multirow[t]{2}{*}{ POWER } & 1800 & & & & & & \\
\hline & Plate & Screen & Grid & Cathode & & & \\
\hline Idc & 104 & 4.0 & 5.6 & 113 & A & & \\
\hline$I(f 1)$ & 181 & 7.7 & 10.6 & 199 & A pk & & \\
\hline Diss & 478 & 4.0 & 1.0 & & $\mathrm{KW}$ & & \\
\hline Efficiency & \multicolumn{2}{|c|}{$79 \%$} & & & & & \\
\hline $\mathrm{ZIN}$ & \multicolumn{2}{|c|}{$3.6 \Omega$} & & & & & \\
\hline$P$ IN & \multicolumn{2}{|c|}{$71 \mathrm{KW}$} & & & & & \\
\hline ANGLE & 0 & 15 & 30 & 45 & 60 & 75 & $90^{\circ}$ \\
\hline VP & 22 & 16.9 & 12.1 & 7.9 & 4.8 & 2.8 & $2.1 \mathrm{KV}$ \\
\hline VCG & 500 & 316 & 145 & -2 & -115 & -186 & $-210 \mathrm{~V}$ \\
\hline IP & 0 & 0 & 69 & 212 & 340 & 409 & $425 \mathrm{~A}$ \\
\hline IG2 & 0 & 0 & 0 & 0 & 7 & 24 & $34 \mathrm{~A}$ \\
\hline IG1 & 0 & 0 & 0 & 1 & 18 & 31 & $37 \mathrm{~A}$ \\
\hline IK & 0 & 0 & 69 & 213 & 364 & 464 & $496 \mathrm{~A}$ \\
\hline
\end{tabular}

Figure 3

Output from Chaffee analysis for an Eimac 4CM2500KG tetrode, using a model as described in this paper.

The process is repeated until the difference between $P x$ and $P o$ is within the desired precision. Fig. 3 is a sample output from such a model for an Eimac 4CM2500KG tetrode.

The above process can be further iterated to obtain data for intervals of output power up to the point of saturation.

\section{Conclusion}

This method has been used extensively at the Princeton Plasma Physics Laboratory and at the MIT Plasma Science Fusion Center. It has proven its worth as a design tool, and as an aid to the tuning and trouble shooting of RF systems.

\section{References}

[1] Eimac, Care and feeding of Power Grid Tubes. San Carlos, CA. 


\section{External Distribution}

Plasma Research Laboratory, Australian National University, Australia

Professor I.R. Jones, Flinders University, Australia

Professor João Canalle, Instituto de Fisica DEQ/IF - UERJ, Brazil

Mr. Gerson O. Ludwig, Instituto Nacional de Pesquisas, Brazil

Dr. P.H. Sakanaka, Instituto Fisica, Brazil

The Librarian, Culham Laboratory, England

Library, R61, Rutherford Appleton Laboratory, England

Mrs. S.A. Hutchinson, JET Library, England

Professor M.N. Bussac, Ecole Polytechnique, France

Librarian, Max-Planck-Institut für Plasmaphysik, Germany

Jolan Moldvai, Reports Library, MTA KFKI-ATKI, Hungary

Dr. P. Kaw, Institute for Plasma Research, India

Ms. P.J. Pathak, Librarian, Insitute for Plasma Research, India

Ms. Clelia De Palo, Associazione EURATOM-ENEA, Italy

Dr. G. Grosso, Instituto di Fisica del Plasma, Italy

Librarian, Naka Fusion Research Establishment, JAERI, Japan

Library, Plasma Physics Laboratory, Kyoto University, Japan

Research Information Center, National Institute for Fusion Science, Japan

Dr. O. Mitarai, Kyushu Tokai University, Japan

Library, Academia Sinica, Institute of Plasma Physics, People's Republic of China

Shih-Tung Tsai, Institute of Physics, Chinese Academy of Sciences, People's Republic of China

Dr. S. Mirnov, TRINITI, Troitsk, Russian Federation, Russia

Dr. V.S. Strelkov, Kurchatov Institute, Russian Federation, Russia

Professor Peter Lukac, Katedra Fyziky Plazmy MFF UK, Mlynska dolina F-2, Komenskeho Univerzita, SK-842 15 Bratislava, Slovakia

Dr. G.S. Lee, Korea Basic Science Institute, South Korea

Mr. Dennis Bruggink, Fusion Library, University of Wisconsin, USA

Institute for Plasma Research, University of Maryland, USA

Librarian, Fusion Energy Division, Oak Ridge National Laboratory, USA

Librarian, Institute of Fusion Studies, University of Texas, USA

Librarian, Magnetic Fusion Program, Lawrence Livermore National Laboratory, USA

Library, General Atomics, USA

Plasma Physics Group, Fusion Energy Research Program, University of California at San Diego, USA

Plasma Physics Library, Columbia University, USA

Alkesh Punjabi, Center for Fusion Research and Training, Hampton University, USA

Dr. W.M. Stacey, Fusion Research Center, Georgia Institute of Technology, USA

Dr. John Willis, U.S. Department of Energy, Office of Fusion Energy Sciences, USA

Mr. Paul H. Wright, Indianapolis, Indiana, USA 
The Princeton Plasma Physics Laboratory is operated by Princeton University under contract with the U.S. Department of Energy.

\author{
Information Services \\ Princeton Plasma Physics Laboratory \\ P.O. Box 451 \\ Princeton, NJ 08543
}

Phone: 609-243-2750

Fax: 609-243-2751

e-mail: pppl_info@pppl.gov

Internet Address: http://www.pppl.gov 